\title{
Inclusion of Children as Active Citizens and Social Work Intervention with Community in Sri Lanka
}

\author{
Varathagowry Vasudevan \\ National Institute of Social Development, Ministry of Primary Industries and Social Empowerment, Sri Lanka \\ E-Mail: gowrynisd@gmail.com
}

\begin{abstract}
Children as citizens are born with civil, political, social and economic rights. Children are considered as active and autonomous individuals, despite the fact that they remain objects of protection and are less visible. Their reduced visibility, is generally seen in activities organized purportedly as events for children's participation achieving other outcomes. Such initiatives proved to be non-events in the case of children's rights. These events underscored the necessity to intervene to establish children's inclusionary position in society. This study therefore addresses the outcomes of social work interventions in communities involving children. The interventions were specifically designed to address issues of active participation of children that promote inclusionary citizenship. In this process attempts were made to promote and inculcate active citizenship values and to create awareness on inclusion policies not only among the younger generation but particularly among the influential, 'opinion making' older members in the community The paper argues that to achieve the full participation of children for their development, interventions from professional social workers are essential. Professionally qualified social workers with wide field experiences play important roles in the promotion of inclusionary policies among community members especially with children. As illustrations, the study uses two community work projects that identify and underscore very clearly instances wherein professional social workers play important roles to revitalize communities for citizenship practices inclusive of children in Sri Lanka.
\end{abstract}

Keywords: Children in Community, Inclusionary Citizenship Policies and Active Citizens

\section{INTRODUCTION}

Children's participation is an integral component for promoting inclusionary policy and active citizenship. A community consisting of individuals possessing common homogenous characteristics also defined on the basis of geographical characteristics or common concerns regarding lifestyles or common socio- cultural orientations may collectively organize their lives as the need arises by laying down norms collectively. For such moves participation of members of a particular community becomes a pre requisite to promote active citizenship and inclusionary policies when work with community in a professional manner. To develop communities it is important to initiate the process by which individuals, families and/or communities assume responsibility for their own welfare and develop a capacity to contribute to their own development as well as to the development of communities. This study addresses children active participation as a value to demonstrate to include children participation in community development activities to empowers communities which in turn brings success to the community self reliance.

Citizenship contributes social integration and stability (Dominelli, 2004). Professional social workers concern with individual and collective well- being of children as active citizens to promote their ability through helping them to help themselves as collectively in definite geographical villages at community level of intervention. It gives way to realize the process in which children were respected and included as active citizens in their community for promoting inclusionary policy at community practice levels.

Community development through citizenship practice is a multi-step process. It is based upon people's collective strength (collective efforts) to help themselves while helping the community. In the opinion of Ife (1995:02) community development achieved through the participation of the community is seen as "the process of establishing, or re- establishing, structures of human community within which new ways of relating, organizing social life and meeting human needs become possible. Thus, community members as active citizens and their participation in the community to relate themselves to the activities that enhance their own development. In this connection, the community work that is practiced by professional social workers could be seen as activities, or practice that seeks to facilitate that process of community development promoting active citizenship policies such as include all ages, individual citizens considered as part of the community and respect differences, self - determination, solidarity and recognize their needs as rights to promote total wellbeing as collective efforts of citizenship practices at community level.

Professional Social workers are also capable of assessing, supporting and intervening into the issues related to the community and its environment on the basis of the principles and the concept of totality. The trainee professional social workers working with communities are normally trained to adapt the multi-disciplinary intervention strategies that they have learnt to cover the complete social continuum of community development. This helps them to investigate the overarching causes/consequences of the community settings related to socio-cultural factors, family relationships, resource availability to resolve the reported 
issues concerning community participation. By doing so they strive to enhance community development that leads to the wellbeing of the said community.

This study endeavors to demonstrate the importance of inclusionary policy and children as active citizens as well as component of community development. It demonstrates the extent to which student social workers use evidence-based knowledge derived from research and practice evaluations to improve children's lives.

\section{METHODOLOGY}

This study attempts to ascertain the extent to which social work interventions by student social workers had contributed to the development of communities through the inclusionary policy and promoting active citizenship. To meet the main objective of this study relating to the importance of inclusionary policy and active citizenship for community development. Selected project reports on community participation carried out by two undergraduates reading for the Bachelor's degree in Social Work at the National Institute of Social Development were used as the main source of data for this study. The two selected undergraduate reports carried out as partial fulfillment for the degree of the Bachelor of Social Work degree were on participation of children in community development. The two student social workers who carried out the project undertook the task of resolving the major issues identified through intervention strategies that they had learnt. This study therefore attempts to provide field based evidence to demonstrate the importance of inclusionary policy and promoting active citizenship for community development and in the process the study also attempts to critique the intervention strategies adopted to ascertain the appropriateness of the measures selected by the social workers.

The data for the two community work project as stated by the authors were obtained through needs assessments. This had enabled the undergraduates to identify the issues and work out appropriate strategies to resolve them through appropriate intervention and guided supervision. While using the project reports as data sources the undergraduates were also interviewed to obtain additional data using open ended questionnaires.

The data and information as given in the reports were used for the study along with additional data that were available with them. In addition the undergraduates were interviewed using an open ended questionnaire. Whenever necessary the unprocessed/raw data and other information and explanation were obtained. The additional information obtained through interviews was mainly qualitative which were very useful and relevant to this study. Information was also obtained from the respective field visit, feedback from children group and community members, faculty and field supervision. An open discussion held with the student social workers on the role of student social workers in promoting inclusionary policy and active citizenship in community development. The collated data were processed to arrive at themes which were used in the presentation of the findings subsequently.

\section{FINDINGS OF THE STUDY}

\section{A. Profile of the Selected Communities}

The two communities selected through identified two villages which are vulnerable in two GN divisions in the Northern Province of Sri Lanka. The selection of villages was on the basis of poverty and need for social work intervention. The total number of families selected was 103 and 243. The villagers were Hindus who were engaged in agricultural and related labor activities. Since these families were resettled in their own villages they were initially comfortable. However majority of them $(90 \%)$ had to encounter difficult economic challenges as they were prevented from rebuilding their livelihoods. Main issues of these villages are socially and geographically isolated and fifteen percentage of them women headed families.

\section{B. Identified Needs}

Common needs of the communities were identified initially by the student social workers through consultative group meetings with members of the communities and service providers of government, non governmental and private organizations of these villages. Need assessment surveys and focused group discussions were held subsequently and observations were undertaken to collect the relevant data. These data were processed and the results were analyzed the outcomes were studied thereafter to list out the common needs. Identified needs were discussed at community meetings and prioritized by the members of the communities. During the discussions a number of suggestions were put forward by the elderly who formed a significant percentage of the population in the two villages. Their propositions were to harness the unused resource among the children for developmental activities as it would benefit the children as well as the others in the communities. Following discussions in this direction the community members came up with the idea of forming small groups (community development group, women group, children club) to work on this process.

\section{Role of Small Groups in Promoting Inclusionary Policy}

As one of the suggestions small groups were formed among community to harness the dormant resources available among the grown up children for community development. This move was an outcome of the survey at the preliminary stages when it became known that families and grown up children had no idea of the concept of community development and the extent to which they could contribute towards this development. The community was found drifting aimlessly. They needed to become aware of their potentiality towards active citizenship. This resource became a major concern of the student social workers. 
While working with small groups and explored with small groups.

\section{Intervention by Student Social Workers}

To facilitate this process the student social workers realized that the communities needed to become aware of the advantages of development. With low levels of education prevalent among the villagers this became an area of concern of the researchers.. Equipped with the art and skills of organizing communities for various needs (Miller et al, 2004 cited from Jim. I). these student social workers organized awareness programmes initially on the importance of education for community development. They emphasized very eloquently the fact that knowledge was power.

As a preparatory measure to convince the villagers on the benefits of organizing themselves for specific needs the student social workers began to undertake home visits simultaneously to engage in informal discussions with members of families on the benefits of development. These informal discussions helped in the building of trust among the community members. As delineated by Rasanayagam and Amerasinghe (2000:40) in their study on social mobilization and poverty alleviation in Monaragala, Sri Lanka informal relationships unlike formal relationships facilitated the emergence of creative talents among the poor. As creative talents are useful and necessary in community development this exercise of exchanging ideas at informal gatherings undertaken by the students social workers have contributed significantly towards the engagement of the young villagers with new suggestions.

The importance of conducting Shramadana was emphasized on the development of genuine enthusiasm and commitment of active citizenship for their collective efforts. The details on power relations were discussed to understand their own strengths and weaknesses to tackle their own conflicts as positive thinking was necessary to focus on common needs rather than focusing on the needs of individuals. Building consensus is an extension of the mediation role which account for the diversity of views at community meetings. It involves emphasizing common goals, identifying common ground and helping community members to move towards a consensus position that is acceptable to all in the community. These common needs bring the community members together to plan the fulfillment of their own common needs.

Group facilitation is a critical task in community work as many of the goals of community development can only be achieved through effective and smooth running of groups which allow mutual decision making and participation by group members. Student social workers used a variety of techniques, strategies and specific roles such as social animation, mediation negotiations, group facilitation, resource link, organizer to facilitate the process of community development. Action committee and children club were given training on communication, leadership and writing letters to service providers. A children's club was helped to establish a village library at the community. The following changes were visibly facilitated by the Student social workers on the community.

1. Importance given to children's opinions to help them take their own decision

2. Promotion of the policy "best interest of the children' (CRC, 1989).

3. Children were given responsibilities in community activities

4. Parents encouraged to have close rapport with children to build positive relationships

5. Child friendly practices

6. Development of the concept of punctuality among the children

7. Encouragement of children's interaction with other children in a bid t reduces social distance based on caste orientated beliefs among the children and their families.

8. Build up interaction neighboring villages through sport activities

9. Anti alcohol campaign at community levels

10. Competitions on drawings and sports

11. Parent enthused to see their children responsibilities and involvement in clubs

12. improvement of children as active citizens in decision making at home and at community levels

13. parents/ community members became vigilant on children at community level

14. Enabled the establishment of community library which encouraged reading habits

15. Enabled Livelihood support to recent IDP returnees (destitute women and Women headed families).

16. Community participation increased at all levels.

"Community development is an ongoing process of learning- community workers are constantly learning new skills, new ways of thinking, new ways of looking at the world, new ways of interacting with others"(Jim, I,1995:210). Community workers get involved in continuous evaluation and feedback with community to enhance continuous changes in the community. Evaluation and feedback such as community discussions, consultation, children club feedback, discussion after each activity of groups and community service providers' feedback were instrumental in facilitating the participation process. Social workers had continuously appreciated individuals' participation and gave importance to collective efforts at community levels. Sometimes it becomes necessary for a student social worker to demystify their thinking on ascribed characteristics of caste traditions in order to accommodate inclusiveness and common consensus. Thus it is important for a student social worker to think carefully before adopting confrontationist tactics if needed. This study critique that Caste based beliefs as formidable challenges to promote inclusionary policy in the said community work scenario. Student social workers achieved 
only to promote inclusionary policy within same caste groups and failed to achieve between caste groups.

Student Social workers in this instance played a vital role in helping community members specially children clubs and community groups to identify skills and community resources (Internal and external resources), and services that were available for them. Children, parents and community members were able to identify the potentials of their community members' skills and expertise. They also learnt details on the availability of community resources, services and facilities which in turn helped the members of the community to identify and locate their resources for use. An example in this context would be the identification of the local nongovernmental organization which helps to promote children happiness. In fact, it may be possible for the Northern hub to be to redeveloped and rehabilitated by maximizing the use of local resources. Such a move would invariably restore the confidence of local communities to stimulate local activity and should be able to build the self confidence, autonomy, self- reliance of the community leading to sustainable development. This was identified as an area where in the community worker could facilitate the development of the community network among the people, to facilitate developmental activities for sustainable development.

Contributions by the community along with maximum use of local resource are very essential for promoting active citizenship and to reduce the dependency problems at micro and macro levels. In this regard, the study revealed that the student social workers did play a crucial role by linking resources \& services to children's clubs and helped to mobilize existing services of government, nongovernmental and private sectors and thereby enhanced specially service delivery to community.

Feedback from the community stated in their own words was very encouraging The statements were; "up to now nobody came to our community like you to listen to our needs and problems and work with us" This statement reveals very clearly that the lack of professional intervention and the absence of people's appreciation of worthy deeds of the professionally trained social workers at community levels. "It created an opportunity for us to show our appreciation of interventions by students social workers at community levels. "We were able to organize our own activities through our clubs in the community". "We found our own resources "When a community takes responsibility for managing their own organizations/ committee / groups to become self- reliance, professional worker should terminates his/her responsibility of facilitation. Whenever community wants to have professional help it may approach relevant professional for facilitating community development process. before terminating the professional role, technical roles such as managing community organizations, managing financial resource and control, keeping minutes, recoding etc need to be ensure structures in place that community organization reflect values of accountability to community members who continue to participate in community development process.

\section{CONCLUSION}

In conclusion it may be surmised that levels of active citizenship practice at individual, family, group and community levels is different but must be facilitated by a professionally trained social worker. Such an intervention is vital to mobilize communities to move away from a state of dependency towards sustained development through active citizenship practices while upholding inclusionary policies. In the analysis it was observed that certain common patterns regarding citizenship practices emerged on the basis of the different understanding of children, families and socio groups identifiable in the community. These findings on the whole have highlighted a number of issues which need to be researched further before using the relevant data in the formulation of welfare policies pertinent to service delivery and service delivery system to community levels. The importance of Social work interventions by;

1. Facilitating community to act as a whole.

2. Facilitating active citizenship.

3. Linking services with community/children's clubs.

4. Incorporating the process of integrated decision making.

The outcomes of the study revealed that from the point of view of children as active citizens there were two major issues to be addressed. These issues identified below were related to the non availability of trained professionals and in government, non government and private social welfare service delivery system in Sri Lanka.

1. Dearth of trained professional in the delivery of social welfare services

2. Provision of social welfare services without concerning active citizenship practices such as service users/ beneficiaries control.

To resolve the issues identified alternative strategies need to be developed through with further studies carried out using a broader coverage. Though it is well known that the ideal solution too many of the problems identified at community levels/ national level.

Finally it is hoped that this study based on the information gathered through the interventions of student social workers in two selected communities using the community organization methodology would serve as powerful demonstration on evidence based practice for use in instances of citizenship practices at community level while upholding inclusionary policies for community development. It recommends that community organization method, obtaining evidence based knowledge ,Enhancing the policy 'best interest of children' for motivating the communities toward community development has underscored the effective interventions that professionally 
trained social workers are capable of, when attempting to revitalize communities for sustainable development to achieve themselves.

\section{REFERENCES}

[1] Chandraratne, D. (2008). Social Work Education \& Practice; A Sri Lankan Perspective. Colombo : Vijitha Yapa Publications.

[2] Colby, I. D. (2004). Introduction to Social Work; The People's Profession. Chicago: Lyceum Books Inc.
[3] Craig, G. (1995). Community Empowerment; A Reader in Participation and Development. New Jersey: Zed Books.

[4] Dominelli, L. (2004). Social Work: Theory and Practice for a changing profession. London : Polity Press.

[5] Jim, I. (1998). Community Development, Creating Community Alternatives- vision, analysis and practice. Longman.

[6] Jowitt, M. a. (2005). Social Work with Children \& Families. Southernhay East : Learning Matters Ltd .

[7] Rasanayagam, Y \& Amarasinge, PD.,(2000). Social Mobilization and Poverty Alleviation in the Moneragala Colombo.

[8] Ross, M. (1955). Community Organization Processes. New York : Prentice Hall. 